\title{
Dasineura gigantea sp.n. (Diptera, Cecidomyiidae) associada a Psidium cattleianum Sabine (Myrtaceae) no Brasil ${ }^{1}$
}

\author{
Alessandro C. Angelo ${ }^{2}$ \\ Valéria Cid Maia ${ }^{3}$
}

\begin{abstract}
Dasineura gigantea sp.n. (Diptera, Cecidomyiidae) associated with Psidium cattleianum Sabine (Myrtaceae) in Brazil. A new species of Dasineura Rondani, 1840 (Diptera, Cecidomyiidae) which causes galls on Psidium cattleianum Sabine, 1821 is described and illustrated (larva, pupa, male, female). The gall is characterized and some biological notes are given.

KEY WORDS. Diptera, Cecidomyiidae, Dasineura, insect galls, Psidium cattleianum
\end{abstract}

Dasineura Rondani, 1840 é o gênero de Cecidomyiidae com maior número de espécies conhecidas, incluindo 110 neárticas (GAGNÉ 1989) e 11 neotropicais (MAIA 1995), cinco das quais com ocorrência no Brasil. Neste gênero, encontram-se espécies galhadores, espécies que vivem livremente em flores e ainda inquilinos de galhas. No Brasil, estão associadas às seguintes famílias de plantas: Asteraceae, Burseraceae, Lamiaceae e Myrtaceae (GAGNÉ 1994).

Neste trabalho, mais uma espécie galhadora associada a Myrtaceae é acrescida ao gênero.

Até então, em Psidium spp. (Myrtaceae), quatro galhas morfologicamente diferentes e foliares haviam sido descritas e registradas no Brasil, (RÜBSAAMEN 1908; TAVARES 1921; HOUARD 1933), porém sem a identificação do inseto galhador. Neste trabalho, são registradas pela primeira vez galhas desenvolvidas a partir de primórdios foliares e botões florais em Psidium Linnaeus, bem como identificado e descrito o agente galhador. Cabe ainda acrescentar que o fruto de Psidium cattleianum Sabine, 1821 é comestível, sendo vulgarmente conhecido como araçá. Segundo LEgRAND \& KLEIN (1977), P. cattleianum ocorre em toda a parte oriental da América do Sul, predominando no Brasil, chegando até o nordeste do Uruguai.

\section{MATERIAL E MÉTODOS}

Galhas em P. cattleianum foram coletadas e transportadas para o laboratório de Proteção Florestal (Curso de Engenharia Florestal, Setor de Ciências Agrárias, Universidade Federal do Paraná), onde parte da amostra foi dissecada para a observação da estrutura interna das galhas e das formas jovens. Outra parte foi

1) Contribuição número 1108 do Departamento de Zoologia, Universidade Federal do Paraná.

2) Departamento de Silvicultura e Manejo, Universidade Federal do Paraná. Rua Bom Jesus 650, 80035-010 Curitiba, Paraná, Brasil. Bolsista do CNPq.

E-mail: alessandro.angelo@bbs2.sul.com.br

3) Museu Nacional, Universidade Federal do Rio de Janeiro. Quinta da Boa Vista, 20940-040

Rio de Janeiro, Rio de Janeiro, Brasil. Bolsista da CAPES. 


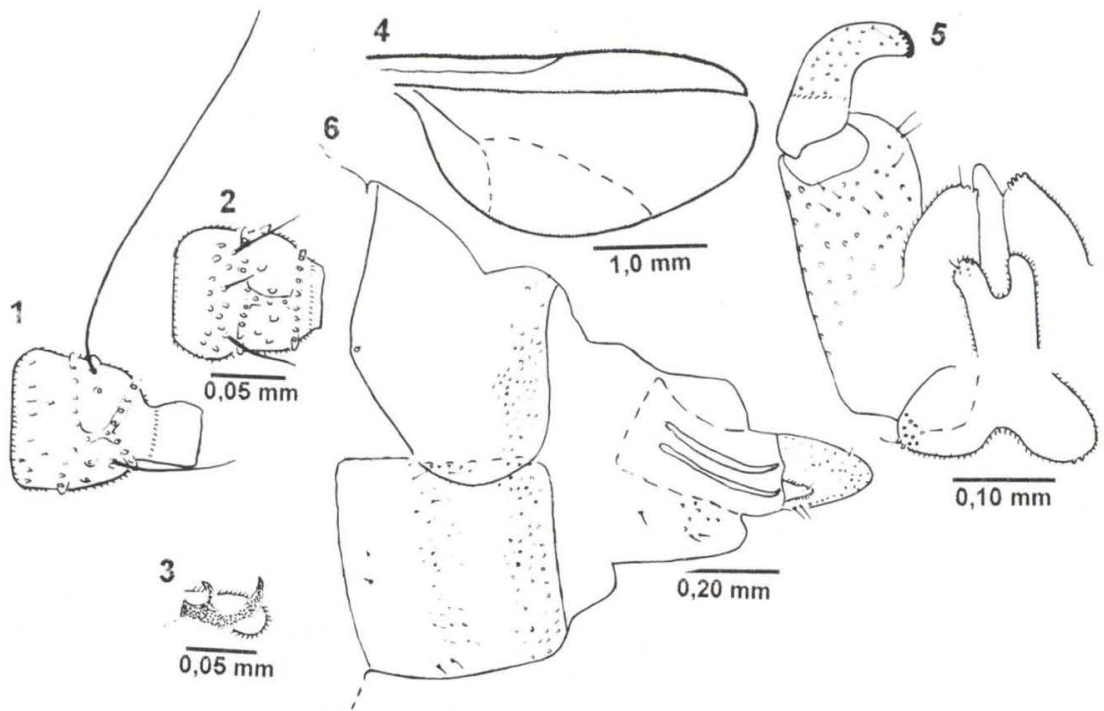

Figs 1-6. Dasineura gigantea sp.n. (1) Flagelômero III, macho; (2) flagelômero III, fêmea; (3) perna II, garra e empódio, macho; (4) asa, fêmea; (5) terminália masculina, vista dorsal; (6) segmentos abdominais VII, VIII e ovipositor, vista lateral.

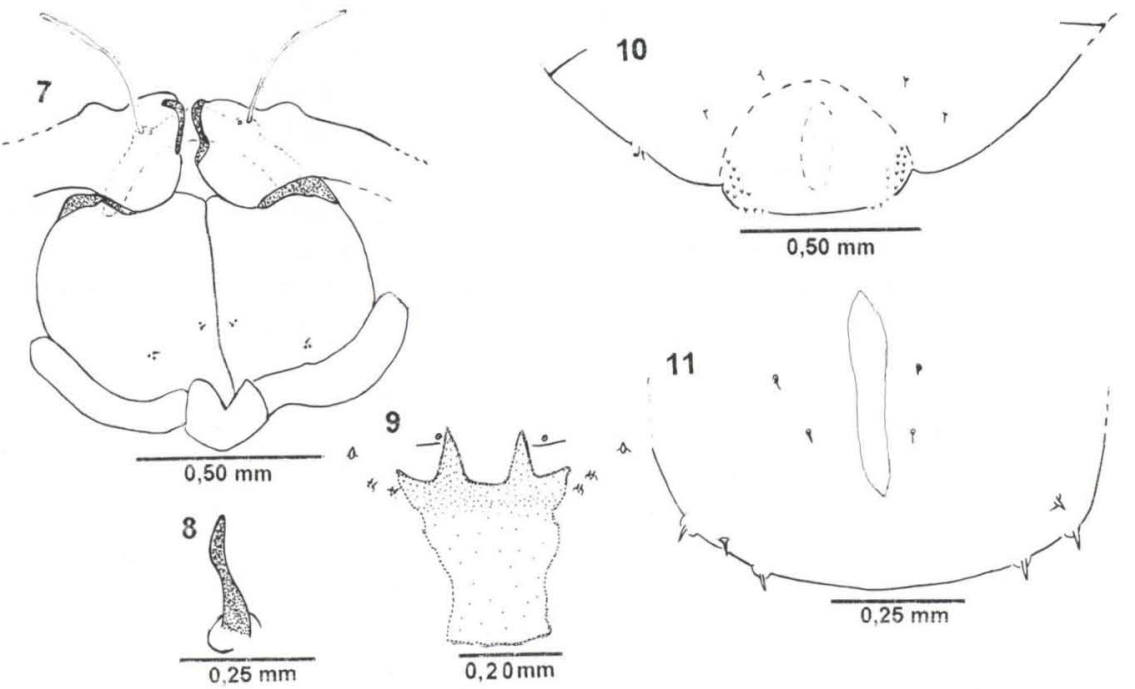

Figs 7-11. Dasineura gigantea sp.n. (7) Pupa, região cefálica, vista ventral; (8). Pupa, espiráculo protorácico; (9) larva, espátula protorácica, papilas esternais, laterais, ventrais, vista ventral; (10) larva, segmento abdominal VIII e terminal, vista dorsal; (11) larva, segmento terminal, vista ventral.

Revta bras. Zool. 16 (1): 191 - 195, 1999 
acondicionada em recipientes plásticos $(5 \mathrm{~cm}$ de altura $\times 4 \mathrm{~cm}$ de diâmetro) forrados na base com papel de filtro umedecido e cobertos na extremidade com "voil", sendo então mantidos em câmaras climatizadas $\left(25 \pm 1^{\circ} \mathrm{C}\right.$ e fotoperíodo de 12 horas) para a obtenção dos adultos.

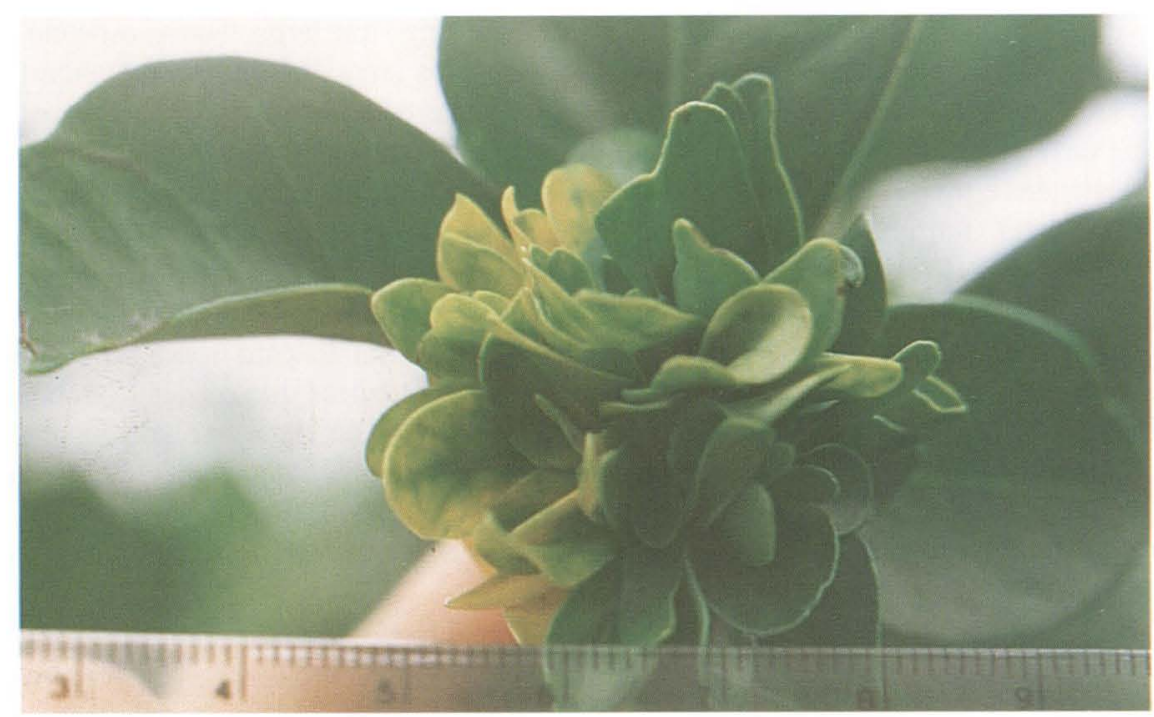

Fig. 12. Dasineura gigantea sp.n., aspecto geral da galha.

Pupas, machos e fêmeas foram montados entre lâmina e lamínula com bálsamo do Canadá, de acordo com a metodologia de GAGNÉ (1989). Larvas de terceiro ínstar foram preparadas segundo a metodologia de MAIA et al. (1996).

O restante do material foi conservado em recipientes com álcool $70 \%$. Amostras da planta hospedeira foram herborizadas (sob número 29492) e depositadas no Museu do Departamento de Botânica da Universidade Federal do Paraná.

O gênero foi identificado a partir da chave de GAGNÉ (1994). Embora a larva de Dasineura gigantea sp.n. possua apenas seis papilas terminais (e não o arranjo típico de oito), incluímos esta espécie em Dasineura, em função dos caracteres dos adultos.

\section{Dasineura gigantea sp.n.}

Figs 1-12

Adulto. Comprimento do corpo: 2,8-4,3 mm; da asa: 2,9-4,5 mm. Corpo com escamas e longas cerdas abundantes e castanhas. Cabeça: olhos negros, face, fronte e occipício amarelos; olhos com facetas hexagonais, facetas mais afastadas entre si no terço superior da cabeça; antenas: escapo triangulóide, pedicelo aproximadamente tão longo quanto largo e 1,23 vezes mais longo que o escapo; 22-24 flagelômeros, 
haste conspícua nos machos e curta nas fêmeas, ornamentação como nas figuras 1 e 2; flagelômero I com 1,33 vezes o comprimento do pedicelo; palpo com quatro artículos: o primeiro curto e 2,5 vezes mais longo que largo; o segundo subigual ao comprimento do primeiro e 1,9 vezes mais longo que largo; o terceiro 1,7 vezes mais longo que o precedente e 4,2 vezes mais longo que largo e o quarto com 0,6 vezes o comprimento do terceiro e 2,7 vezes mais longo que largo. Tórax; escutelo, pleuras e nervuras alares castanho-escuros; halteres amarelos, pernas castanhas; escudo, anepímero, anepisterno, catepímero e pleuras com grupos de cerdas discais; pernas: garras com $0,02 \mathrm{~mm}$ de comprimento, curvas próximo ao terço basal, denteadas e mais longas que o empódio (Fig. 3). Asas como na figura 4. Abdome: no macho: tergitos e esternitos retangulares e cerdosos; na fêmea: tergitos e esternitos I-VI retangulares, esclerotinizados e cerdosos; tergitos VII e VIII como na figura 6. Terminália masculina (Fig. 5): gonocoxito robusto, gonóstilo mais largo na base e acentuadamente curvo; edeago delgado, afilando para a extremidade; parâmeros desenvolvidos e cerdosos, um pouco mais curtos que o edeago; hipoprocto alcançando cerca da metade do comprimento do parâmero, cerdoso e bilobado (lobos delgados, afastados um do outro e arredondados apicalmente); cerco cerdoso, bilobado (lobos amplos e divergentes) e mais curto que o hipoprocto. Ovipositor protrátil, 2,5 vezes mais longo que o esternito VII; cercos fundidos e cerdosos (Fig. 6).

Pupa. Comprimento do corpo: $3,7 \pm 0,25 \mathrm{~mm}(\mathrm{n}=5)$. Região cefálica (Fig. 7): chifres antenais bem desenvolvidos, com $0,03 \mathrm{~mm}$ de comprimento e bidenteados (dente externo mais longo que o interno); dois pares de papilas verticais (um cerdoso e outro nu), cerda apical com $0,03 \mathrm{~mm}$ de comprimento; três pares de papilas frontais laterais (um cerdoso e dois nus); dois pares de papilas frontais inferiores (um cerdoso e outro nu). Tórax: espiráculo protorácico amarelado, longo (0,04 $\mathrm{mm}$ de comprimento), basicônico, curvo, afilando em direção à extremidade (Fig. 8). Cobertura das pernas anteriores, médias e posteriores alcançando, respectivamente, a região sub-basal do segmento abdominal $\mathrm{V}$, a região subapical do mesmo segmento e a região subapical do segmento VI. Espinhos dorsais abdominais ausentes.

Larva de terceiro ínstar: comprimento do corpo: 4,9-5,1 mm; amarela. Espátula protorácica bidenteada (dentes triangulares), haste curta e desenvolvimento lateral conspícuo; três pares de papilas laterais externas (dois cerdosos e um nu) e três pares de laterais internas (dois cerdosos e um nu). Papilas esternais nuas. (Fig. 9). Papilas dorsais com uma cerda curta. Espiráculos laterais nos segmentos abdominais I-VII, deslocados em direção ao centro no segmento VIII. Papilas terminais e anais como nas figuras 10 e 11 .

Ovos. Comprimento: $0,37 \pm 0,01 \mathrm{~mm}(\mathrm{n}=10)$, forma elíptica, cerca de 5,0 vezes mais longo que largo. Número médio de ovos postos por fêmea $(n=4)$ : 111 , 25.

Material-tipo: Brasil, Paraná: Piraquara, holótipo macho, 20-IX-1996 (data de emergência), (galha coletada em 08-VIII-1996), Alessandro C. Angelo leg. (MNRJ, Museu Nacional do Rio de Janeiro). Parátipos: mesmo coletor, BRASIL, Paraná: Piraquara, 2 exúvias, 09-XI-1995; 3 larvas, 11-IV-1997. Pontal do Paraná, 7 larvas, 13-V-1997. Obtidos de galhas em Psidium cattleianum (Myrtaceae); Santa 
Catarina: Itapoá, 2 fềmeas, 17-X-1996 (data de emergência), (galhas coletadas em 01-X-1996); 1 fêmea, 14-X-1996 (data de emergência), (galha coletada em 29-VIII1996); 3 larvas, 13-V-1997 (MNRJ). Paraná: Piraquara, 1 fêmea, 31-VIII-1996 (data de emergência), (galha coletada em 08-VIII-1996), 1 macho, 30-VIII-1996 (data de emergência), (galha coletada em 08-VIII-1996); Santa Catarina, Itapoá, 1 macho, 16-X-1996 (data de emergência), (galha coletada em 01-X-1996); 2 larvas, 28-III-1996 (DZUP, Departamento de Zoologia, Universidade Federal do Paraná).

Galha (Fig. 12): desenvolvida a partir de primórdios foliares e eventualmente de botões florais. Os primórdios foliares atacados não se desenvolvem normalmente, resultando em folhas menores e aglomeradas. Coloração: verde a princípio; galha madura com aspecto "lenhoso". Número de câmaras internas: de 1 a 16 (média: 3,$47 ; n=260$ ). Número de larvas por câmara: uma; período de ocorrência: bivoltino, iniciando-se predominantemente nos meses de fevereiro-abril e agosto-outubro.

Etimologia. O epíteto específico refere-se ao grande comprimento do corpo do adulto (tamanho médio na família: 2,0-3,0 mm).

\section{REFERÊNCIAS BIBLIOGRÁFICAS}

GaGnE, R.J. 1989. The Plant-Feeding Gall Midges of North America. Ithaca, Comstock Cornell University Press, 356p.

. 1994. The Gall Midegs of the Neotropical Region. Ithaca, Comstock Cornell University Press, 352p.

Houard, C. 1933. Les Zoocécidies des Plantes de l'Amérique du Sud et de l'Amérique Central. Paris, Hermann et Cie, $519 \mathrm{p}$.

Legrand, C.D. \& R.M. Klein. 1977. Myrtaceae. Flora Ilustrada Catarinense. Itajaí, Herbário Barbosa Rodrigues, 158p.

MAIA, V.C. 1995. Três espécies novas de Dasineura Rondani (Diptera, Cecidomyiidae) associadas a Myrtaceae na Restinga da Barra de Maricá, Rio de Janeiro. Revta bras. Zool. 12 (4): 1001-1008.

MAIA, V.C.; M. DE S. MENDONÇA JR. \& H.P. RoMANOWSKI. 1996. Eugeniamyia dispar gen.n. and sp.n. (Diptera, Cecidomyiidae, Lasiopteridi) associated with Eugenia uniflora L. (Myrtaceae) in Brazil. Revta bras. Zool. 13 (4): 1087-1090. TAVARES, J.S. 1921. Cecidologia brazileira. Cecídias que se criam em plantas das famílias das Leguminosae, Sapotaceae, Lauraceae, Myrtaceae, Punicaceae, Aurantiaceae, Malpighiaceae, Sapindaceae, Umbelliferae, Loranthaceae, Apocynaceae, Urticaceae, Salicaceae e Gramineae. Brotéria, Sér. Zool., 19: 76-112. RÜBSAAMEN, E.H. 1908. Beiträge zur Kenntnis aussereuropäischer Zoocecidien. III. Beitrag. [cont.]: Gallen aus Brasilien und Peru. Marcellia 7: 15-79.

Recebido em 29.IX.1997; aceito em 19.XI.1998. 